\title{
Experiment on of Nozzle Flow with Sudden Expansion at Mach 1.1
}

\author{
Mohammed Faheem, Mohammed Kareemullah, Abdul Aabid, Imran Mokashi, S. A. Khan
}

\begin{abstract}
This present study discusses the outcome of the experimental investigations, and the efficacy of the tiny jets used to regulate the base pressure as well as the wall pressure in suddenly expanded flow. The control mechanism as tiny jets having a cross-section of $1 \mathrm{~mm}$ diameter was employed as the base pressure regulator at the exit periphery of the nozzle. The experiments were carried out to investigate and record the flow field at the rear end of the separated flow region for area ratio 4.84. Four tiny jets were placed at a distance of $6.5 \mathrm{~mm}$ away from the primary jet coming from the nozzle exit at ninety degrees apart, and the tiny control jets were flowing at sonic Mach number. The actual Mach number of the main jet was 1.1. The experimentation was accomplished at a different level of expansion (i. e., $N P R=3,5,7,9$, and 11) and the $L / D$ ratio considered was from 10 to 1 . This study mainly focuses on the development of the flow in the suddenly expanded duct, nature of the flow in the duct, and the impact of the Control on the wall pressure and the magnitude of the pressure along the duct. The wall pressure in the smooth duct is not unfavorably influenced by the control jets.
\end{abstract}

Keywords-CD Nozzle, Microjet, Wall Pressure, and Mach number.

\section{INTRODUCTION}

Investigators in the area of external dynamics have long been wondering about the low pressure and the flow separation at the blunt base or at the backward-facing step. At the blunt base, when the flow separates the flow is divided into two regions. One is the separated zone, which separates it from the main jet, and the other is being the wake region or the recirculation corner flow. The pressure in the wake/separated region will be less than the ambient pressure, which results in the drag penalty in the case of external aerodynamics. This penalty in terms of the base drag is substantial at the transonic Mach numbers. Once, the flow is reattached with the duct wall, from the reattachment point again; the boundary layer will grow.

While scanning the literature, it is observed that at transonic speed, the contribution of the base drag is significant due to the low pressure/sub-atmospheric pressure at the base corner. This may account for around seventy percent of the net value of the drag. The researcher also tried to optimize the skin friction drag as well as the wave drag,

Mohammed Faheem, Dept. of Mechanical Engineering, Faculty of Engineering, International Islamic University, Kuala Lumpur, Malaysia

Mohammed Kareemullah,Dept. of Mechanical Engineering P. A. College of Engineering, Nadupadav, Kairangala, Mangalore.

Abdul Aabid,Dept. of Mechanical Engineering, Faculty of Engineering, International Islamic University, Kuala Lumpur, Malaysia. Engineering, International Islamic University, Kuala Lumpur, Malaysia.

S. A. Khan, Dept. of Mechanical Engineering, Faculty of Engineering, International Islamic University, Kuala Lumpur, Malaysia, (sakhan@iium.edu.my)
Revised Manuscript Received on August 19, 2019.

Imran Mokashi,Dept. of Mechanical Engineering, Faculty of

but there is no more scope to reduce the drag. Skin friction will be there by virtue of the wetted surface area of the aerodynamic vehicles, and we do not have any control as there is a requirement from the end-user of the space department. Further, the wave drag is bound to be present due to the formation of the shock waves at the nose portion of the projectiles/missiles/shells at supersonic Mach numbers. However, the wave drag will be least if the nose fineness ratio is between 2.5 to 4 .

In view of the above situation, the researchers in the field of external ballistics are mostly concentrating on controlling the base pressure, which is a significant concern. Another primary concern and aspect while studying the base flows are whether to study by internal flow techniques or the external flow techniques. If we decide and opt to use the external flow methods for our investigations, then there are so many problems which are associated with the external flow study. One of them is the requirement of abundant air supply and to do that we need heavy-duty compressor which will consume enormous electrical power at the same time there is a requirement of larges storage tanks to store the air. In the present scenario, there is an acute shortage of energy. Hence, we need to look for other alternative methods which will result in energy savings in view of the depletion of the energy sources, and especially the fossil fuels which are likely to get exhausted in few years.

Since the study of the flow field around the aerodynamic bodies by means of the external aerodynamics is not feasible due to the cost involved in it, another significant disadvantage of external aerodynamics is that due to the presence of support mechanism it will cause a lot of errors in the measured data. The support mechanism and sting will introduce the errors in the measurements. Another problem with the external aerodynamics is how to avoid the influence of the boundary layer in the test section.

In this study, we opted for internal flow methods to study the base pressure flow field. It is well known that for lower Mach number the disturbances created will propagate all along in the circular waveform. But when Mach number is unity, there will be a normal shock wave, and the entire area is vertically divided into two halves. Once the flow Mach number is more than unity an oblique shock will be formed at the nose of the shell/missile/rocket/bomb which will further reduce the zone of action and zone of silence will be around seventy-five percent.

Hence, we can state that the internal and external flow is principally the same. In the case of external flow, the flow 
tends to go inward from the point of flow separation, whereas, in the case of internal flow, they will follow the outward trend. The significant advantage in the internal flow study is that the quantum of air supply needed will be reduced significantly. Another advantage is that we can measure the temperature as well as the pressure along the wall of the duct. Moreover, there is no error involved in the measurement as all the support mechanism has been eliminated.

From the last four decades, the number of investigations has been done using the experimental method in a supersonic flow regime; some of them highlighted in this section. Convergent-divergent nozzle with suddenly expanded axisymmetric ducts enhanced the microjets to control the base pressure and experimentally investigated the effectiveness of the microjets. Also, they measured the static wall pressure, and the nature of the flow suddenly expanded duct. The results show that for a given inertia level and nozzle pressure ratio (NPR) one can find the L/D ratio which will result in a maximum enhancement/decrement in the pressure in the wake region [1].

An experimental investigation has been done for a CD nozzle with the suddenly expanded duct to regulate the base pressure and to accomplish these micro jets were employed in the form of tiny jets as a control mechanism. For active control air injected from four points at the base area of the duct and control is symmetric to the axis of the CD nozzle. Also, the static wall pressure and the quality of the flow field along the duct length was investigated. From the results proved that for a known level of inertia and the nozzle pressure ratio (i.e., expansion level (NPR)), we could freeze the duct length, Mach number, and the NPR, which will result in the optimum results [2].

The experimental method was used to investigate the effectiveness of microjets at the base of the nozzle. The jets at all Mach numbers were ideally expanded. From the results, it shows that the microjets can control the pressure at the base called base pressure active control and proved that the wall pressure distribution would have favorable influence by the microjets [3] from the experimental method optimized the effectiveness of microjets at suddenly expanded duct of the convergent-divergent, convergent nozzles.

Micro jest placed at 90 degrees having $1 \mathrm{~mm}$ diameter is adopted as active controls. These jets were located at $1.3 \mathrm{x}$ the nozzle exit diameter in the base region. The wall pressure levels in the duct, as well as the quality of the flow, was investigated in the presence and absence of the control. From the results of the wind tunnel tests, it was evident that for a fixed level of inertia and the level of expansion one can find the optimum duct length and the relief to the flow which will result in a most significant increment/decrement of pressure at the base corner. Ref. [4] Khan and Radhakrishnan experimentally investigated, to study the effects of the control mechanism in fixing the base pressure values in the case of suddenly expanded axisymmetric ducts. They investigated the wall pressure in the sudden duct and found that the microjets can serve as a capable controller for the base pressure, which can reduce the base suction by many folds. From the investigation, it has been proved that for a fixed value of area ratio of the duct, the level of inertia, and the level of expansion one can arrive at the optimum duct L/D ratio that will, in turn, result in most significant hike/fall of base pressure [5].

Khan and Radhakrishnan experimentally investigated the possibility of using four tiny jets when the flow is impacted by all the three possible levels of expansion (i.e., correct, over, and under expanded) to limit the pressure in the duct at the base point. Results revealed that for Mach, 2.58, around one fifty two percent increase in base pressure is achieved easily with the powerful microjets. The wall pressure is uniform and does not get influenced by the use of jets. Also, it shows that microjets can serve as an active controller raising the base suction to almost zero levels for some combination for parameters [6].

Experimentally investigated the base pressure control in a suddenly expanded axisymmetric duct, and the microjets will put a favorable impact on the wall pressure and information on the internal supersonic flow [7]. Airflow from convergent-divergent axisymmetric nozzles expanded suddenly into a circular enlarged pipe of the larger crosssectional area than that of nozzle exit area are investigated through the wind tunnel, mainly focusing on the control of base pressure and the development of the flow in the enlarged duct.

They concluded from their wind tunnel tests that the dynamic control in the form of injecting the air from the control stagnation chamber through the tiny jets in the form of circular pipe of $1 \mathrm{~mm}$ diameter exiting with the sonic Mach number is able to regulate the pressure in the wake, and at the same time they do not aggravate the quality of the flow and do reduce the suction and augment the base pressure in the duct and finally reduce the base drag [8]. In Ref. [9]-[12] studied the wall pressure distribution flow after control the base pressure using microjet controller. Active and passive control using small cylinder well studied experimentally [13]-[17]. Khan et al., [18]-[20] investigated the number of studies for base pressure control in a CD nozzle and the effectiveness of the microjets and also, the flow field inside the across the duct length.

On the other hand, using the method of computational fluid dynamics from ANSYS commercial code, some investigations have been found from the last decades, few of them are specified here. An ANSYS was used for numerical simulation to find out the effectiveness of microjets to restrain the base pressure in suddenly expanded twodimensional convergent-divergent nozzle. The CD nozzle geometry was modeled and simulated employing turbulence models: K- $\varepsilon$ standard wall function turbulence model from the code was independently checked with the commercial computational fluid dynamics [21]-[26] and twodimensional axisymmetric model also been used to model the nozzle in some cases of the studies [27]-[34].

Khan et al., [35], [36] applied CFD method to analyze the supersonic flow over the wedge and no-circular cylinder [37]. From the above literature, it has been observed there is no work stated with active control to study the effect of wall 
pressure distribution at transonic Mach number especially at Mach number $\mathrm{M}=1.1$ for various area ratios but in this case area ratio is 4.84 . Therefore, in the present work, an effort is made to investigate the flow development in the duct as well as the wall pressure and increment or decrement in its magnitude with and without active control by the micro jets as a control mechanism under the influence of favorable pressure gradient.

\section{EXPERIMENTAL WORK}

The experimental results have shown that the projectile base pressures are related to the type of boundary layer, its thickness, and its point of location. The same concept is used to perform the experimental investigation with the application of four microjets at the base, as shown in Fig. 1.

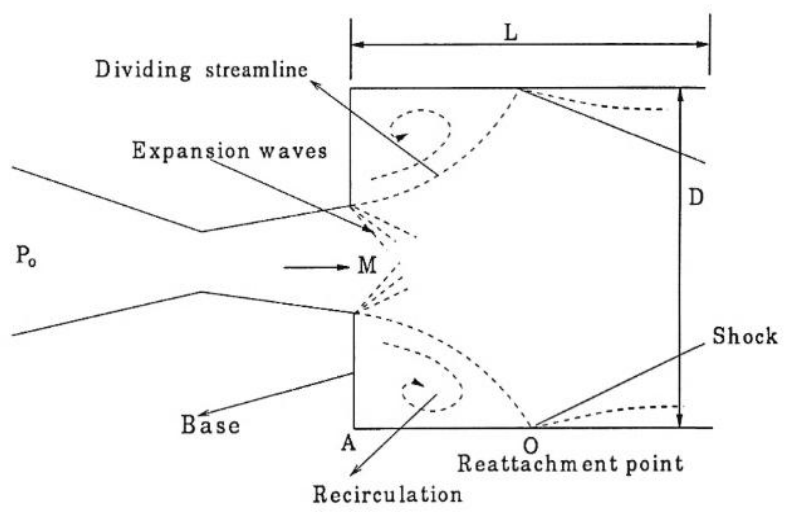

Figure 1: A view of the Flow Field with Sudden Expansion

Fig. 2 demonstrates the setup used for the experiment in the present study, which is also discussed in [1]. The investigation was performed using experimental setup made of pipelines, settling chamber which is used to hold the model to be tested, and the pressure transducers. The gas can pass through the values assigned earlier and regulated there and adequately through the model of experimentation. Duct attached to the nozzle is the experimental model employed with the settling chamber there. The flow starts expanding from the nozzle and getting separated and reaching the wall of the duct getting reattached in the downstream of the duct. In the later part of the enlarged duct is exposed to ambient atmospheric pressure.

Fig. 3 show the remaining arrangement involved in the experimental setup. At the nozzle exit and base of the duct 1 $\mathrm{mm}$, holes are made for injection of the air from the control chamber. The total pressure in the control chamber is the same as the stagnation pressure in the main settling chamber. Eight holes are drilled in the base of the nozzle at the pitch circle diameter of $13 \mathrm{~mm}$ to control the base pressure. The holes marked as ' $\mathrm{C}$ ' are meant for blowing the air from the control chamber through the microjets. The other four holes at the base are connected to the pressure transducer to measure the base pressure at the base area.

The pressure along the length of the duct was recorded through the wall pressure taps which were provided to measure and record the wall pressure along with the quality of the flow in the duct. The instrument used to record the pressure has its range from the 0-15 bar, and it has 16 channels. The sampling rate of the pressure transducer is 250 samples in one second, and then the reading is displayed on the monitor of the desktop of the PC and also, recorded on the hard disk of the computer. The wall pressure was recorded by the pressure transducer using the remaining ten channels.

These channels are used for the initial length of the enlarged duct. Since the flow will get reattached with the duct wall within $\mathrm{L} / \mathrm{D}=2$ to 3 , this initial length is very critical as the flow will undergo a lot of changes in the flow parameters. Once the flow is exiting will undergo expansion due to a sudden increase in the area and flow is allowed to expand.

When the flow is passing through the converging nozzle, the nozzle will get choked when NPR $=1.89$. This will happen under ideal conditions. Here while deriving the relations, the flow is assumed to be isentropic. But in reality, the flow will never be an isentropic flow. While assuming the flow to be isentropic, the effects of viscosity and the boundary layers are neglected.

It is also should be mentioned here that the flow will turbulent and also the boundary layer too will be turbulent. Hence the flow from the converging nozzle may be ideally expanded or under expanded. But when the flow is passing through a converging-diverging nozzle, it will have three conditions. The flow can be correctly, over or under expanded. When the flow is under expanded, the jet will undergo through the expansion wave where the expansion of the flow will take place.

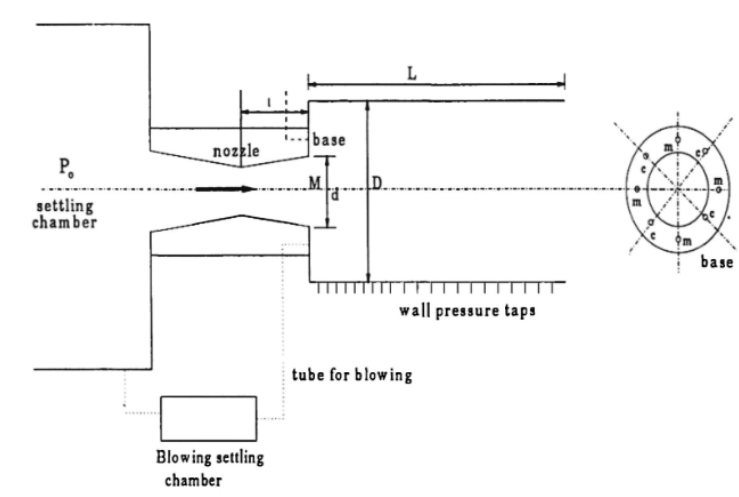

Figure 2: A View of the Experimental Setup.

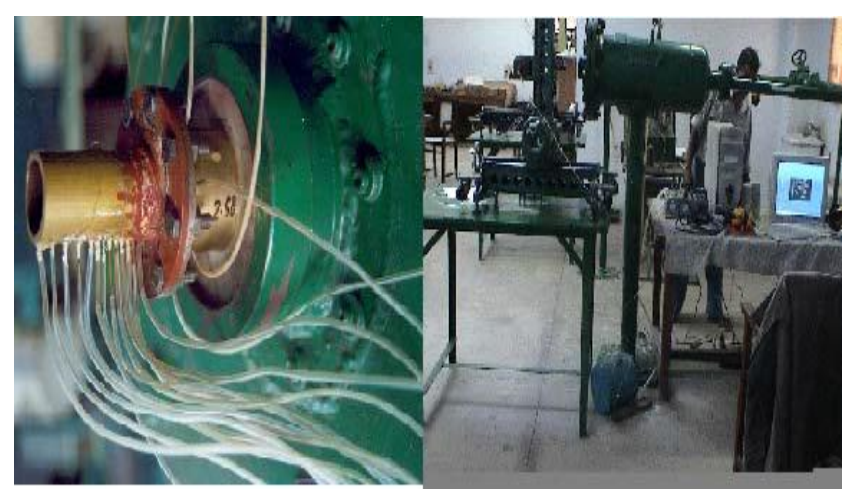

Figure 3 A View of the Duct with Pressure Tapings and setup location 
The ideally expanded jets will undergo the Mach waves across which the flow will be isentropic, and losses will be absent. When the flow is over expanded, then there be an oblique shock wave at the nozzle lip through which the pressure will increase, and the formation of the waves will continue until the jets have attained the ambient atmospheric pressure. The measurement of the wall pressure at the remaining points was recorded using multi-tube mercury manometer.

\section{RESULTS AND DISCUSSION}

The wall pressure results for area ratio 4.84 are presented in Figs. 4, for Mach number M 1.1, and for all the L/Ds of the investigations. This area ratio of 4.84 , in this case, due to the increase in the diameter of the enlarged duct. Therefore this is a case of slightly increased relief for the expanding flow when compared with the area ratio of 3.24 since the location of the microjets as the control mechanism, was fixed at PCD of 1.3. Hence due to the increase in the relief available to the flow, the microjets have further shifted away from the base and tend to go near the main jet. The results show that the microjets do have a positive influence on the wall pressure field.

In view of the control mechanism being far away from the base region, it may not influence the recirculation zone in the base region. Under these circumstances, when the control in the form of the microjets are activated, they proceed and follow the main jets without affecting the flow field in the base region of the duct wall. It is seen from the results that, for $\mathrm{L} / \mathrm{D}=10$ and for the inertial level when the Mach number $\mathrm{M}=1.1$ the control is impervious to the wall pressure (as in the case of the lower area ratios the pressure at the wall is marginally influenced).

Further, it is seen that for NPR's 3, 5, and 7 the fluctuations in the wall pressure level attains steady state within $15 \%$ of the duct diameter length. Whereas for rest of the NPRs in the range from 9 to 11 the flow field, by and large, the flow remained oscillatory, however, the magnitude of the oscillations is less as compared to the previous case because for increased enlarged duct area the free shear layer will relaxed relatively. It is also seen that within ten percent of the duct length, there is a massive jump in the wall pressure. At the highest level of under expansion, the wall pressure is forty percent greater than the ambient atmospheric pressure. Fig. 4 (b) presents similar wall pressure results for $\mathrm{L} / \mathrm{D}=8$ as was observed in the previous figure with the much-reduced oscillations due to the reduction in the duct length. Due to the reduction in the duct length, the suction created at $\mathrm{L} / \mathrm{D}=10$ will get reduced due to the reduced duct length.

For this case, the peak value of the wall pressure for NPR $=11$ remained as that of $\mathrm{L} / \mathrm{D}=10$. Also, the magnitude of the wall pressure has come down for this decreased length. For lower NPRs, the recovery of the wall pressure is rapid. Figs. 4 ((c) to (d)) represent the wall pressure results for L/D $=6$ and 5 with the exception that due to the reduction in the $\mathrm{L} / \mathrm{D}$ ratio (i.e., the duct length) there is some influence of the ambient atmospheric pressure (back pressure), and also the magnitude of the peak wall pressure has come down. The wall pressure values are higher than that those who were observed for higher L/D ratios namely for the case it is L/D
$=5$ with the twenty percent increase in the value of the peak wall pressure value in comparison to the ambient pressure which was forty percent more than the free stream ambient pressure to that of at $\mathrm{L} / \mathrm{D}=6$. It is also seen that the flow field has become smooth in the duct as observed earlier, and the wall pressure values with and without control have identical values. Small variations which were noticed for higher L/Ds are no more seen here for this L/D.

This trend continues until $\mathrm{L} / \mathrm{D}=4,3$, and 2 (Figs. $4((\mathrm{e})$ to (g)), then later for lowest $\mathrm{L} / \mathrm{D}$ like $\mathrm{L} / \mathrm{D}=1$, it is evident that this length is not enough for the flow to remain attached with the duct wall and hence we should not draw any inference and the conclusions from these results of the duct wall. At higher NPRs, namely 9 and 11 initially, the wall pressure is enhanced by forty percent for L/Ds in the range 10 to 8 . Again at $\mathrm{L} / \mathrm{D}=6$ this peak value of the wall pressure remained at twenty percent. However, at Lower L/Ds in the range from 5 to 3, the wall pressure again attains the peak values more than forty percent of the free stream ambient atmospheric pressure. But with a further decrease in the enlarged duct length, i.e., at $\mathrm{L} / \mathrm{D}=2$, again there is a further increase in the wall pressure.

For the duct length $\mathrm{L} / \mathrm{D}=2$, the peak value of the wall pressure is fifty percent more than the backpressure within fifteen percent of the duct length. Another peculiar phenomenon is seen at the lower duct length at $\mathrm{L} / \mathrm{D}=2$ is that at NPR $=11$, the peak wall pressure has shifted towards the downstream and is located at the twenty percent of the duct length. For lower values of the level of expansion, namely NPR $=9$, the peak values are at the same location as at $\mathrm{X} / \mathrm{D}=0.2$, which is the twenty percent of the duct length. At NPR $=7$ the peak wall pressure values are nearly equal to the ambient atmospheric pressure. Even for the duct length $\mathrm{L} / \mathrm{D}=1$, flow is found to be attached with the duct wall at NPR in the range from 5 to 11 . When the jets are correctly expanded, and at NPR $=3$, the flow is unable to attach itself with the duct wall. Hence, we cannot draw any definite conclusions, and these results may be neglected while analyzing the results with the sudden expansion at sonic and transonic Mach numbers.

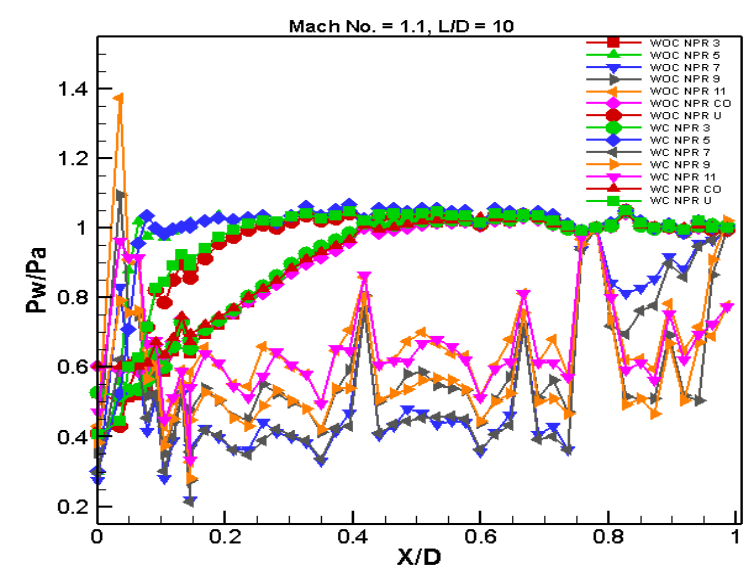

(a) 


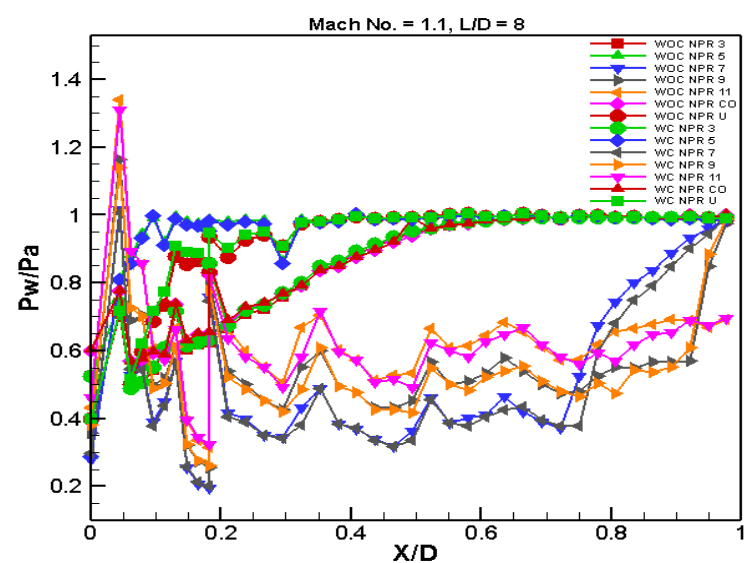

(b)

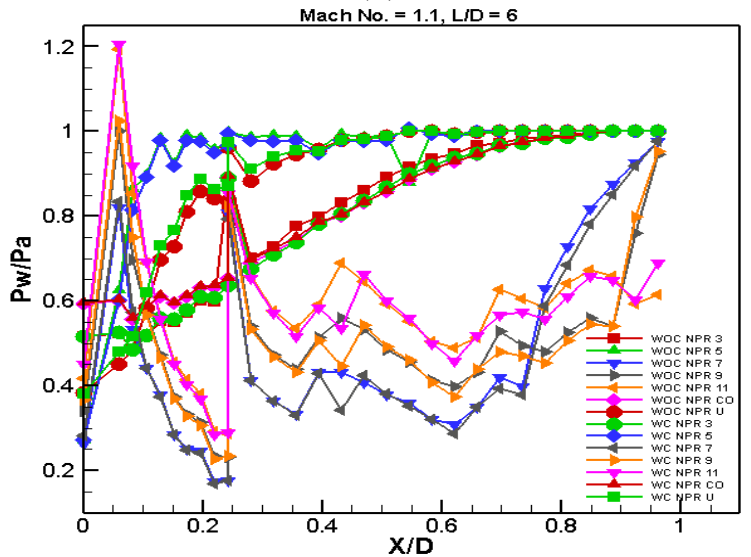

(c)

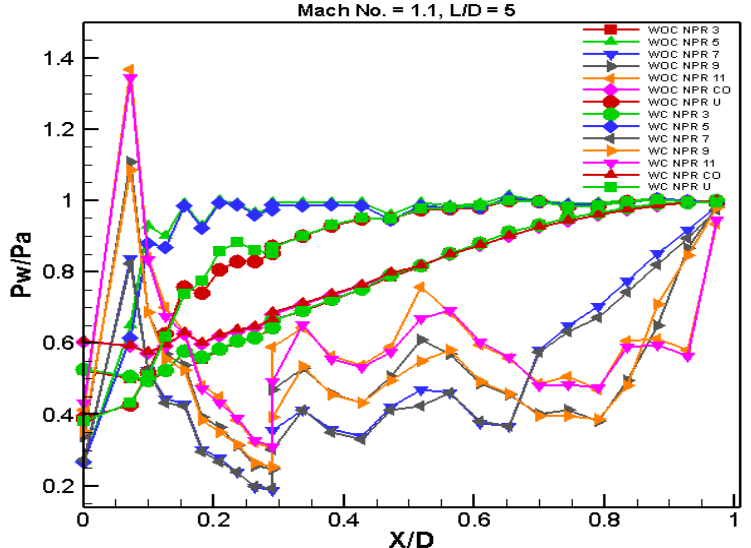

(d)

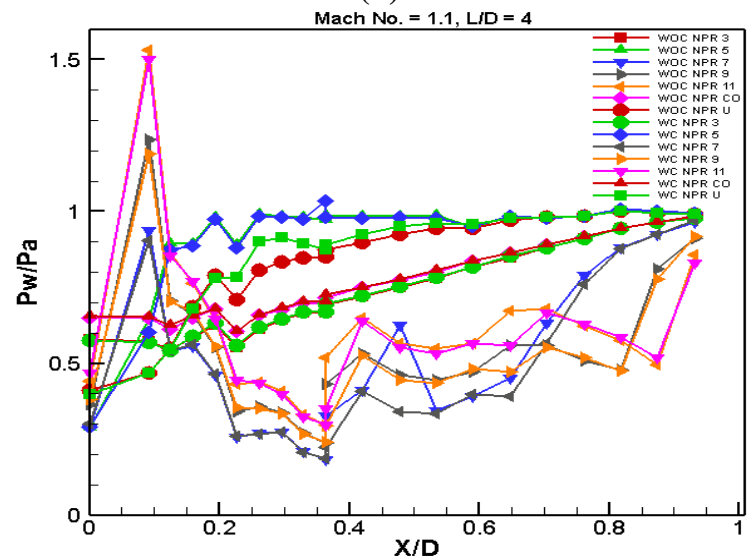

(e)

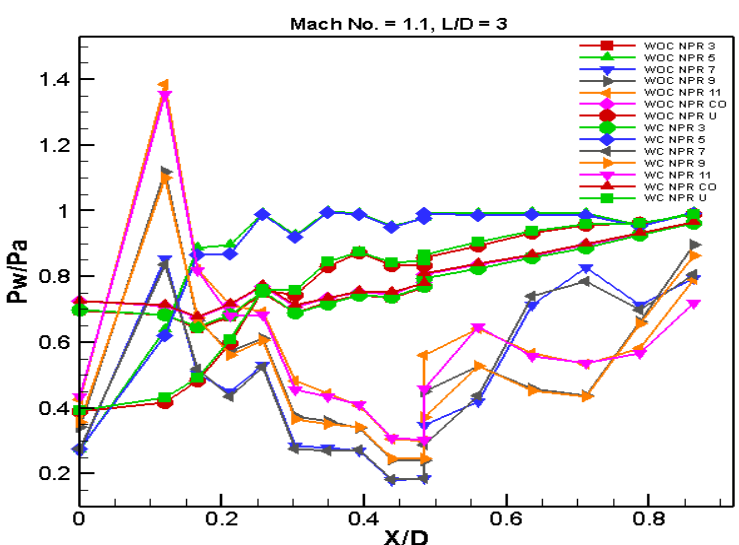

(f)

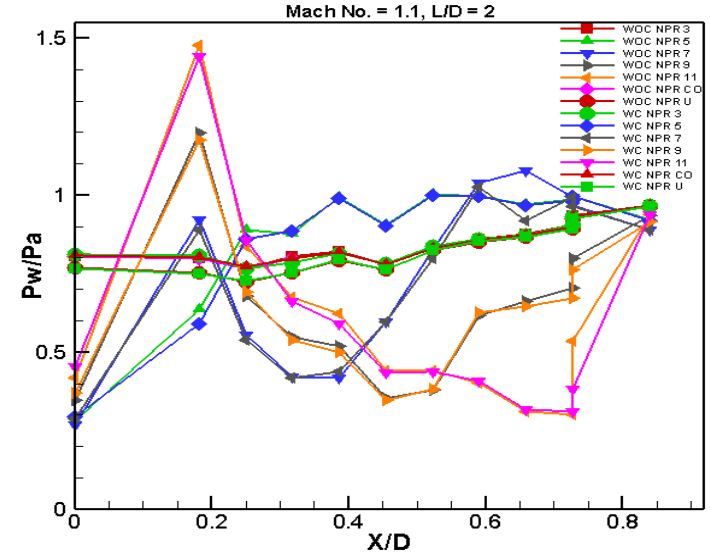

(g)

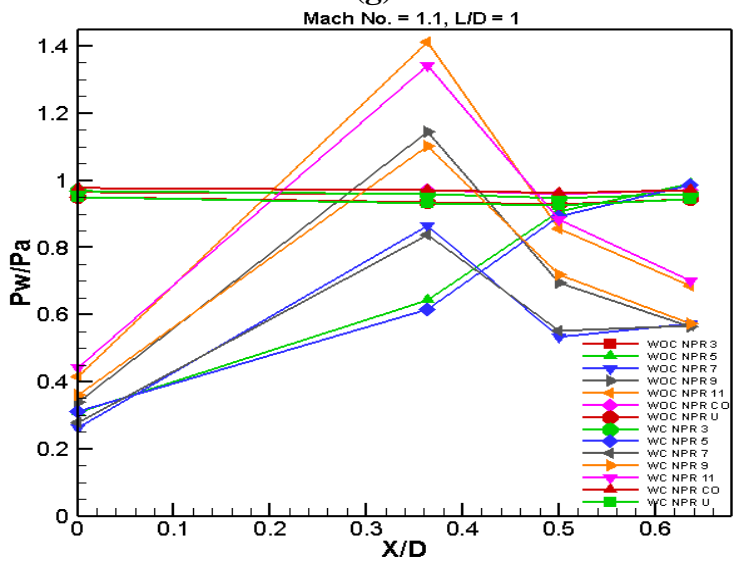

(h)

Figure 3. Wall pressure distribution

\section{CONCLUSION}

Based on the above discussion of wall pressure investigation and the influence of the micro jets and its net effect on wall pressure distribution alongside with the duct in which the gas expands suddenly from a convergingdiverging nozzle is carried out in this work the following conclusions can be drawn:

- The analysis performed deals with the application of active control as the microjets with and without control.

- Microjets, as an active control located at the base of the nozzle, is used at PCD 1.3. The duct area ratio and the nozzle are 4.84 at a Mach number of nozzle equal to 1.1 .

Published By:

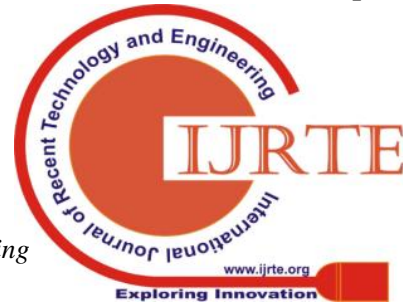


- The duct length to diameter changed, starting from 10 to 1 in the step of 1 each. From the detailed comparative analysis of having no control and full control, the wall pressure is found to be assuming a minimum for area ratio 4.84 and L/D from 10 to 1 at Mach numbers 1.1.

- At higher NPRs, namely 9 and 11 initially, the wall pressure is enhanced by forty percent for L/Ds in the range 10 to 8 . Again at $L / D=6$ this peak value of the wall pressure remained at twenty percent.

- However, at Lower L/Ds in the range from 5 to 3, the wall pressure again attains the peak values more than forty percent of the free stream ambient atmospheric pressure.

- But with a further decrease in the enlarged duct length, i.e., at $\mathrm{L} / \mathrm{D}=2$, again there is a further increase in the wall pressure.

- For the duct length $\mathrm{L} / \mathrm{D}=2$, the peak value of the wall pressure is fifty percent more than the backpressure within fifteen percent of the duct length.

- Another peculiar phenomenon is seen at the lower duct length at $\mathrm{L} / \mathrm{D}=2$ is that at NPR $=11$, the peak wall pressure has shifted towards the downstream and is located at the twenty percent of the duct length.

- For lower values of the level of expansion, namely $\mathrm{NPR}=9$, the peak values are at the same location as at $\mathrm{X} / \mathrm{D}=0.2$, which is the twenty percent of the duct length.

- At NPR = 7 the peak wall pressure values are nearly equal to the ambient atmospheric pressure.

- Even for the duct length $\mathrm{L} / \mathrm{D}=1$, flow is found to be attached with the duct wall at NPR in the range from 5 to 11

- When the jets are correctly expanded, and at NPR = 3, the flow is unable to attach itself with the duct wall.

- Hence, we cannot draw any definite conclusions, and these results may be neglected.

- The use of micro jets resulted in a decrement of suction at the base and decrease of associated drag at these combinations of parameters, resulting in an eighty-three percent increase in base pressure.

- Lastly, active control does not have an adverse impact on the duct wall pressure distribution and the flow field.

\section{REFERENCES}

1. S. A. Khan and E. Rathakrishnan, "Active Control of Suddenly Expanded Flows from Overexpanded Nozzles," Int. J. Turbo Jet Engines, vol. 19, pp. 119-126, 2002.

2. S. A. Khan and E. Rathakrishnan, "Control of Suddenly Expanded Flows with Micro-Jets,” Int. J. Turbo Jet Engines, vol. 20, pp. 63-82, 2003.

3. S. A. Khan and E. Rathakrishnan, "Control of Suddenly Expanded Flows from Correctly Expanded Nozzles,” Int. J. Turbo Jet Engines, vol. 21, pp. 255-278, 2004.

4. S. A. Khan and E. Rathakrishnan, "Active Control of Suddenly Expanded Flows from Underexpanded Nozzles," Int. J. Turbo Jet Engines, vol. 21, pp. 233-254, 2004.

5. S. A. Khan and E. Rathakrishnan, "Active Control of Suddenly Expanded Flows from Underexpanded Nozzles - Part II,” Int. J. Turbo Jet Engines, vol. 22, pp. 163-183, 2005.
6. S. A. Khan and E. Rathakrishnan, "Control of suddenly expanded flow," Aircr. Eng. Aerosp. Technol. An Int. J. vol. 78, no. 4, pp. 293309, 2006.

7. S. Rehman and S. A. Khan, "Control of base pressure with micro-jets : part I," Aircr. Eng. Aerosp. Technol., vol. 80, no. 2, pp. 158-164, 2008.

8. M. Ahmed and A. L. I. Baig, "Active control of base pressure in suddenly expanded flow for area ratio 4 . 84," Int. J. Eng. Sci. Technol., vol. 4, no. 05, pp. 1892-1902, 2012.

9. S. A. Khan, A. Aabid, and Z. I. Chaudhary, "Influence of Control Mechanism on the Flowfield of Duct at Mach 1.2 for Area Ratio 2.56," Int. J. Innov. Technol. Explor. Eng., vol. 8, no. 6S4, pp. 1135$1138,2019$.

10. M. H. Azami, M. Faheem, A. Aabid, I. Mokashi, and S. A. Khan, "Inspection of Supersonic Flows in a CD Nozzle using Experimental Method,” Int. J. Recent Technol. Eng., vol. 8, no. 2S3, pp. 996-999, 2019.

11. M. H. Azami, M. Faheem, A. Aabid, I. Mokashi, and S. A. Khan, "Experimental Research of Wall Pressure Distribution and Effect of Micro Jet at Mach,” Int. J. Recent Technol. Eng., vol. 8, no. 2S3, pp. 1000-1003, 2019.

12. S. A. Khan, I. Mokashi, A. Aabid, and M. Faheem, "Experimental Research on Wall Pressure Distribution in C-D Nozzle at Mach number 1.1 for Area Ratio 3.24," Int. J. Recent Technol. Eng., vol. 8, no. 2S3, pp. 971-975, 2019.

13. S. A. Khan, M. Asadullah, and J. Sadiq, "Passive Control of Base Drag Employing Dimple in Subsonic Suddenly Expanded Flow," Int. J. Mech. Mechatronics Eng., vol. 8, no. 03, pp. 69-74, 2018.

14. S. A. Khan and M. Asadullah, "Passive Control of Base Drag in Compressible Subsonic Flow using Multiple Cavity," Int. J. Mech. Prod. Eng. Res. Dev., vol. 8, no. 4, pp. 39-44, 2018.

15. M. Asadullah, S. A. Khan, W. Asrar, and E. Sulaeman, "Low-Cost Base Drag Reduction Technique,” Int. J. Mech. Eng. Robot. Res., vol. 7, no. 4, pp. 428-432, 2018.

16. M. Asadullah, S. A. Khan, W. Asrar, and E. Sulaeman, "Passive control of base pressure with the static cylinder at supersonic flow," in IOP Publishing House, IOP Conf. Series: Materials Science and Engineering, 2018, pp. 1-10.

17. M. Asadullah, S. A. Khan, W. Asrar, and E. Sulaeman, "Active control of base pressure with the counter-clockwise rotating cylinder at Mach 2," 2017 4th IEEE Int. Conf. Eng. Technol. Appl. Sci., vol. 8, no. 6, pp. 1-6, 2017.

18. J. D. Quadros, S. A. Khan, and A. J. Antony, "Effect of Flow Parameters on Base Pressure in a Suddenly Expanded Duct at Supersonic Mach number Regimes using CFD and Design of Experiments," J. Appl. Fluid Mech., vol. x. No. x, 2016.

19. Z. I. Chaudhary, V. B. Shinde, M. Bashir, and S. A. Khan, "Experimental Investigation on the Effectiveness of Active Control Mechanism on Base Pressure at Low Supersonic Mach Numbers," in In Innovative Design and Development Practices in Aerospace and Automotive Engineering, 2017, pp. 197-209.

20. J. D. Quadros, S. A. Khan, and A. A. J., "Modelling of Suddenly Expanded Flow Process in Supersonic Mach Regime using Design of Experiments and Response Surface Methodology," J. Comput. Appl. Mech., vol. 49, no. 1, pp. 149-160, 2018.

21. A. Khan, A. Aabid, and S. A. Khan, "CFD analysis of convergentdivergent nozzle flow and base pressure control using micro-JETS," Int. J. Eng. Technol., vol. 7, no. 3.29, pp. 232-235, 2018.

22. A. G. M. Fharukh, A. A. Alrobaian, A. Aabid, and S. A. Khan, "Numerical Analysis of Convergent-Divergent Nozzle Using Finite Element Method,” Int. J. Mech. Prod. Eng. Res. Dev., vol. 8, no. 6, pp. 373-382, 2018.

23. S. A. Khan and A. Aabid, "CFD Analysis of CD Nozzle and Effect of Nozzle Pressure Ratio on Pressure and Velocity For Suddenly Expanded Flows," Int. J. Mech. Prod. Eng. Res. Dev., vol. 8, no. June, pp. 1147-1158, 2018.

24. A. Aabid, N. M. Mazlan, M. A. Ismail, N. Akhtar, and S. A. Khan, "Numerical Simulation of Suddenly Expanded Flow at Mach 2.2," Int. J. Eng. Adv. Technol., vol. 8, no. 3, pp. 457-462, 2019.

25. S. A. Khan, A. Aabid, and C. A. Saleel, "Influence of Micro Jets on the Flow Development in the Enlarged Duct at Supersonic Mach number," Int. J. Mech. Mechatronics Eng. IJMME-IJENS, vol. 19, no. 01 , pp. 70-82, 2019. 
26. S. A. Khan, A. Aabid, F. A. G. M, A. A. Al-Robaian, and A. S Alsagri, "Analysis of Area Ratio In a CD Nozzle with Suddenly Expanded Duct using CFD Method," CFD Lett., vol. 11, no. 5, pp. 61-71, 2019.

27. T. J. Ajoko and T. J. Tuaweri, "Design Optimisation of ConvergentDivergent Aircraft Nozzle," vol. 8, no. 1, pp. 9-16, 2017.

28. K. A. Pathan, P. S. Dabeer, and S. A. Khan, "Effect of nozzle pressure ratio and control jets location to control base pressure in suddenly expanded flows," J. Appl. Fluid Mech., vol. 12, no. 4, pp. 1127-1135, 2019.

29. K. A. Pathan, P. S. Dabeer, and S. A. Khan, "Optimization of Area Ratio and Thrust in Suddenly Expanded Flow at Supersonic Mach Numbers," Case Stud. Therm. Eng., 2018.

30. K. A. Pathan, P. S. Dabeer, and S. A. Khan, "Investigation of base pressure variations in internal and external suddenly expanded flows using CFD analysis," CFD Lett., vol. 11, no. 4, pp. 32-40, 2019.

31. K. A. Pathan, P. S. Dabeer, and S. A. Khan, "Influence of Expansion Level on Base Pressure and Reattachment Length," CFD Lett., vol. 11, no. 5, pp. 22-36, 2019.

32. K. A. Pathan, S. A. Khan, and P. S. Dabeer, "CFD Analysis of Effect of Area Ratio on Suddenly Expanded Flows," in 2nd International Conference for Convergence in Technology (I2CT) CFD, 2017, pp. 1192-1198.

33. K. A. Pathan, S. A. Khan, and P. S. Dabeer, "CFD Analysis of Effect of Mach number , Area Ratio, and Nozzle Pressure Ratio on Velocity for Suddenly Expanded Flows," in 2nd International Conference for Convergence in Technology (I2CT) CFD, 2017, pp. 1104-1110.

34. K. A. Pathan, S. A. Khan, and P. S. Dabeer, "CFD Analysis of Effect of Flow and Geometry Parameters on Thrust Force Created by Flow from Nozzle," in 2nd International Conference for Convergence in Technology (I2CT) CFD, 2017, pp. 1121-1125.

35. S. A. Khan, A. Aabid, and A. S. C, "CFD Simulation with Analytical and Theoretical Validation of Different Flow Parameters for the Wedge at Supersonic Mach Number," Int. J. Mech. Mechatronics Eng. IJMME-IJENS, vol. 19, no. 01, pp. 170-177, 2019.

36. S. A. Khan, A. Aabid, I. Mokashi, A. A. Al-Robaian, and A. S. Alsagri, "Optimization of Two-dimensional Wedge Flow Field at Supersonic Mach,” CFD Lett., vol. 11, no. 5, pp. 80-97, 2019.

37. M. F. M. Sajali, A. Aabid, S. A. Khan, F. A. G. M, and E. Sulaeman, "Numerical Investigation of Flow Field of a Non-Circular Cylinder Numerical Investigation of Flow Field of a Non-Circular Cylinder,' CFD Lett., vol. 11, no. 5, pp. 37-49, 2019. 